\title{
Erratum: Constructivism-led assistive technology: An experiment at a Namibian special primary school
}

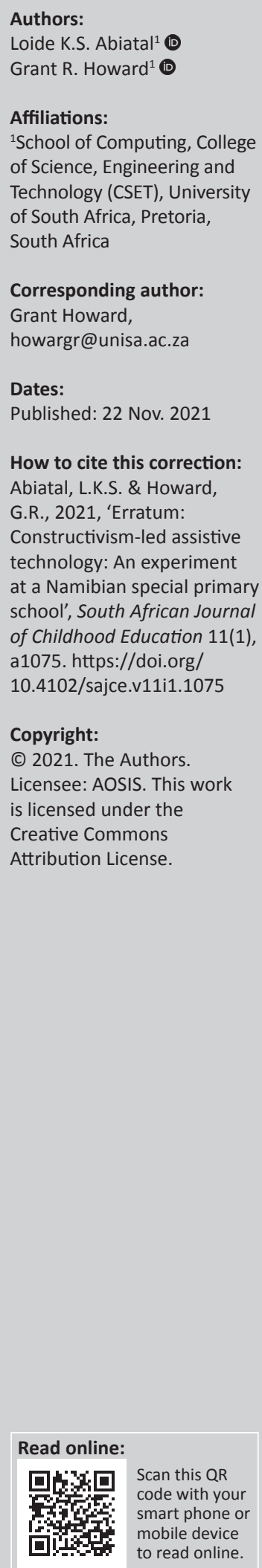

In the version of the article initially published, Abiatal, L.K.S. \& Howard, G.R., 2020, 'Constructivism-led assistive technology: An experiment at a Namibian special primary school', South African Journal of Childhood Education 10(1), a794. https:/ / doi.org/10.4102/sajce.v10i1.794, the article section was given incorrectly. The correct section should be Original Research instead of Review Article.

This correction does not alter the study's findings of significance or overall interpretation of the study's results. The publisher apologises for any inconvenience caused. 